\title{
Seminal Vesicle Schwannoma
}

National Cancer Institute

\section{Source}

National Cancer Institute. Seminal Vesicle Schwannoma. NCI Thesaurus. Code C161639.

A schwannoma that affects the seminal vesicle. 